\title{
Scaffold hunter: visual analysis of biological activity data
}

\author{
Karsten Klein ${ }^{1}$, Oliver Koch ${ }^{2^{*}}$, Nils Kriege ${ }^{3}$, Petra Mutzel $^{3}$, Till Schäfer ${ }^{3}$ \\ From 9th German Conference on Chemoinformatics \\ Fulda, Germany. 10-12 November 2013
}

The growing interest in chemogenomics approaches over the last years has led to a vast amount of data regarding chemical and the corresponding biological activity space. The discovery of new chemical entities is not suitable to a fully automated analysis, but can greatly benefit from tools that allow exploring this chemical and biological space. We present a new version of Scaffold Hunter [1,2], a highly interactive tool that fosters the systematic visual exploration of compound and bioactivity data. The software supports the integration of data from various sources and provides several complementary analysis and visualization modules (Figure 1).

Scaffold Hunter features the scaffold tree algorithm to provide hierarchical classification schemes and offers several interconnected views reflecting different aspects of the data. As a further extension state of the art clustering techniques are now included that allow, for example, to create subsets based on fingerprint similarity. A key concept of Scaffold Hunter is to support a cyclic, iterative knowledge discovery process, where it is possible to refine subsets, adjust the parameters of analysis algorithms or the mapping of property values to visual attributes.

We give an overview over the various views, the workflow concept and present an exemplary analysis of screening datasets targeting T. cruzi and T. brucei, the causative agent of sleeping sickness and Chagas disease, respectively. Scaffold Hunter is platform-independent

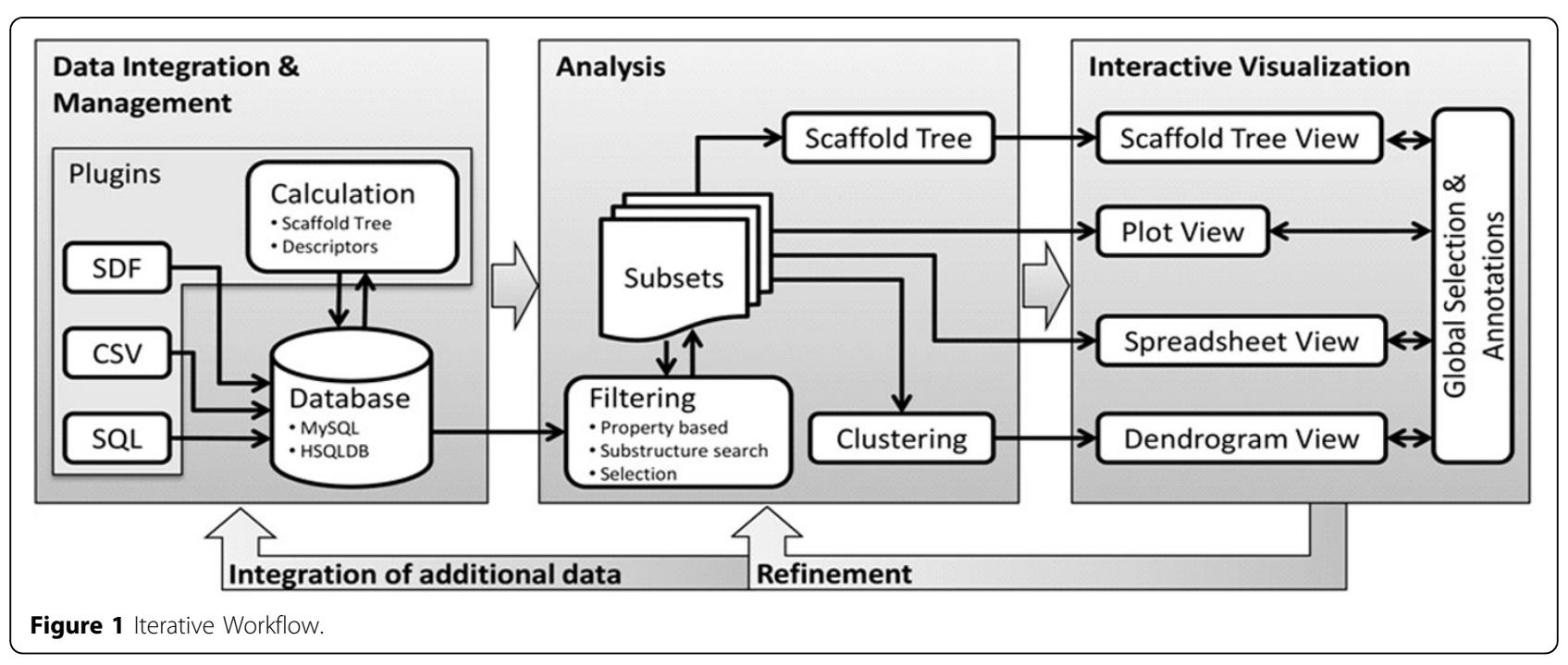

* Correspondence: oliver.koch@tu-dortmund.de

${ }^{2}$ Department of Chemistry and Chemical Biology, TU Dortmund, Germany

Full list of author information is available at the end of the article 
and freely available under the terms of the GNU GPL v3 at http://scaffoldhunter.sourceforge.net/.

\section{Authors' details}

'School of Information Technologies, The University of Sydney, Australia,

${ }^{2}$ Department of Chemistry and Chemical Biology, TU Dortmund, Germany.

${ }^{3}$ Department of Computer Science, TU Dortmund, Germany.

Published: 11 March 2014

\section{References}

1. Wetzel S, Klein K, Renner S, Rauh D, Oprea TI, Mutzel P, Waldmann H: Interactive exploration of chemical space with Scaffold Hunter. Nat Chem Biol 2009, 5:581-583.

2. Klein K, Koch O, Kriege N, Mutzel P, Schäfer T: Visual Analysis of Biological Activity Data with Scaffold Hunter. Mol Inf 2013.

doi:10.1186/1758-2946-6-S1-P33

Cite this article as: Klein et al:: Scaffold hunter: visual analysis of biological activity data. Journal of Cheminformatics 2014 6(Suppl 1):P33.

\footnotetext{
Publish with ChemistryCentral and every scientist can read your work free of charge

"Open access provides opportunities to our colleagues in other parts of the globe, by allowing anyone to view the content free of charge." W. Jeffery Hurst, The Hershey Company.

- available free of charge to the entire scientific community

- peer reviewed and published immediately upon acceptance

- cited in PubMed and archived on PubMed Central

- yours - you keep the copyright

Submit your manuscript here:

hubmit your manuscript here:
http://www.chemistrycentral.com/manuscript/<smiles>c1ccccc1</smiles> 